Editorial

\title{
Bioactivity of Inositol Phosphates
}

\author{
Ivana Vucenik ${ }^{1,2}$
}

1 Department of Medical and Research Technology, University of Maryland School of Medicine, 100 Penn Street, Baltimore, MD 21201, USA; ivucenik@som.umaryland.edu; Tel.: +1-(410)-706-1832; Fax: +1-(410)-706-5229

2 Department of Pathology, University of Maryland School of Medicine, Baltimore, MD 21201, USA

Citation: Vucenik, I. Bioactivity of Inositol Phosphates. Molecules 2021, 26, 5042. https://doi.org/10.3390/ molecules 26165042

Received: 13 August 2021

Accepted: 17 August 2021

Published: 20 August 2021

Publisher's Note: MDPI stays neutral with regard to jurisdictional claims in published maps and institutional affiliations.

Copyright: (C) 2021 by the author. Licensee MDPI, Basel, Switzerland. This article is an open access article distributed under the terms and conditions of the Creative Commons Attribution (CC BY) license (https:// creativecommons.org/licenses/by/ $4.0 /)$.
Inositol phosphates (IPs) are a huge and complex family of biomolecules, important in regulating vital cellular functions, signal transduction, energy transmission, and ion channels physiology and serving as structural components of cell membranes. Inositol hexaphosphate $\left(\mathrm{IP}_{6}\right.$ or $\mathrm{InsP}_{6}$ or phytic acid) and its parent compound myo-inositol (Ins) are the most abundant, naturally occurring, and widely distributed among plants and mammals' tissues.

In this special issue, a selection of research and review articles cover a wide range of bioactivity of inositol phosphates from occurrence to chemistry and methods for their determination, highlighting the broad spectrum of biological activities vital in health and diseases.

Reviewing specific signaling functions for IPs in different cell types, with new information regarding their cellular roles and cellular production, Maffucci and Falasca highlight the interaction of IPs with several proteins, protein complexes, and modulation of enzymatic activity, essential in regulation of several cellular processes [1], and discuss the possibility of new pharmacological opportunities and interventions that modulation of IPs levels can provide in multiple diseases, including cancer [1]. Inositol pyrophosphates (PP-IPs), such as 5-diphosphoinositol pentakisphosphate $\left(5-\mathrm{IP}_{7}\right)$, are inositol metabolites containing high-energy phosphoanhydride bonds, involved in many key biological processes, including growth, vesicular remodeling, and energy homeostasis. The current understanding of how PP-IPs control mammalian cellular signaling networks in physiology and disease is summarized by Lee et al. [2]. IPs may also have distinctive properties in energy production, which is finely tuned to the metabolism and is known to be modulated by several signaling pathways, such as Akt/mTOR, in which IPs are key players [3]. Comparing plants and humans, Cridland and Gillaspy underline lessons we have learned from plants [4]. While eukaryotes have developed complex signaling pathways to adapt to a readily changing environment, in plants and humans, IPs have been implicated in phosphate and energy sensing. PP-IPs are synthesized from the phosphorylation of $\mathrm{IP}_{6}$, the most abundant IP. The plant PP-IP synthesis pathway is similar, but distinct from that of the human, reflecting differences in how molecules such as $\mathrm{IP}_{3}$ and $\mathrm{IP}_{6}$ function in plants vs. animals. In this review, they compare $\mathrm{IP}_{6}$ synthesis pathways, synthesis and regulation of the PP-IPs, and function of a specific protein domain called the Syg1, Pho1, Xpr1 (SPX) domain in binding PP-IPs and regulating inorganic phosphate sensing, providing novel insights into the biosynthetic pathway and bioactivity of these key signaling molecules in plant and human systems [4]. Of course, phosphorus (P) in plants is an essential nutrient, and IPs, particularly $\mathrm{IP}_{6}$, are important stores of $\mathrm{P}$ in plants.

Determination of IPs in biological fluids is difficult. From the early precipitation-based techniques, introduced more than a century ago, to the latest development of enzymatic bio- and nano-sensor applications, the analysis of $\mathrm{IP}_{6}$ and/or other IPs has never been a straightforward analytical task [5]. Due to the biomedical importance, several types of methodologies have been investigated over the years to develop a reliable determination of these intriguing analytes in many types of biological samples [5]. During the past 30 years, researchers have identified many important health benefits of $\mathrm{IP}_{6}$, inositol(s), and IPs. 
However, 150 years have elapsed since the discovery of $\mathrm{IP}_{6}$ to the first descriptions of its beneficial effects. This long delay may be due to the difficulty in determining phytate and other IPs in biological media, as discussed by Grases and Costa-Bauza [6], who dedicated a lot of time in developing methods for analyzing IPs in tissues and biological fluids.

Multiple beneficial effects on human health are related to IPs, and only few are highlighted here. Although $\mathrm{IP}_{6}$ is recognized as a strong antioxidant due to its specific configuration and properties of inhibiting hydroxyl radical formation, very few in vivo studies exist. Aguree et al. [7] examine the protective effect of $\mathrm{IP}_{6}$ in reducing the oxidative stress in a very specific animal model of human hereditary hemochromatosis, showing that $\mathrm{IP}_{6}$ protects against oxidative stress induced by genetic iron overload and high fat diets in $\beta 2$-microglobulin knockout mice [7]. Blocking pathological calcifications is another property related to specific structure of $\mathrm{IP}_{6}$. It has been shown that $\mathrm{IP}_{6}$ and IPs have high capacity to inhibit calcium salt crystallization and that oral or topical administration of $\mathrm{IP}_{6}$ significantly decreases the development of pathological calcifications [6]. However, $\mathrm{IP}_{6}$ and Ins have recently received much attention for their roles in cancer prevention and treatment. A striking, consistent, and reproducible anticancer activity has been demonstrated in different experimental models and systems, targeting several key molecular targets, such as PI3K/Akt, mTOR, MAPK, PKC, and NF- $\mathrm{kB}$. A few clinical studies have shown that $\mathrm{IP}_{6}$ alone or in combination with Ins is able to enhance the anticancer effect of conventional therapy, control cancer metastases, and improve quality of life. The historical perspectives, from the first experiments, concepts, and hypotheses to the first clinical observation in colon cancer patients is presented here [8], and that was the base of several clinical trials conducted later [9]. It is important that the prior research in the field is recognized and that credits are attributed properly. The potential of Ins and IPs in prevention and treatment of inflammatory bowel diseases, particularly colitis and colitis-induced carcinogenesis, was reviewed [10]. To better understand the molecular mechanisms of the anticancer action of IPs, Kapral et al. conducted the study on the involvement of microRNAs and showed that $\mathrm{IP}_{6}$ exerted its biological functions by downregulating the miR-155 expression in human colon cancer cells [11]. However, the synergistic effect of $\mathrm{IP}_{6}$ and Ins was observed not only in cancer [8] but also in metabolic diseases. This combination has been beneficial in regulation of insulin secretion and was effective in the management of type 2 diabetes mellitus [12]. So, inositol(s) may also have distinctive properties in energy metabolism and metabolic disorders $[3,13]$. Targeting the inositol pyrophosphate biosynthetic enzymes in metabolic diseases is a possible therapeutic approach [13]. The $\mathrm{IP}_{6} \mathrm{~K}$ pathway is a potential target in obesity and other metabolic diseases [13]. Furthermore, $\mathrm{IP}_{6} \mathrm{~K}$ isoforms have been proposed as possible targets for cancer therapy [14]. That is not surprising, because both insulin resistance and cancer share several perturbed but critical biochemical pathways, and interestingly both are affected by inositol. Moreover, because of the role of insulin signaling and hormonal synthesis in the ovaries, and involvement of Ins in a number of biochemical pathways within oocytes, the beneficial effect of Ins, D-chiro-inositol, and their combination was shown in polycystic ovarian syndrome (PCOS) by improving the metabolic, hormonal, and reproductive aspects of PCOS [15].

In conclusion, there has been fascination for plants stretching back to millennia, and humans have remained dependent on plants for medicines. The plant kingdom is rich with organic compounds for traditional medicine, as well as for the development of novel agents to improve human health, as was shown for $\mathrm{Ins} \mathrm{IP}_{6}$, and IPs.

Acknowledgments: The Guest Editor wishes to thank all the authors for their contribution to this special issue, to all reviewers, and to the editorial staff of Molecules.

Conflicts of Interest: The author declares no conflict of interest.

\section{References}

1. Maffucci, T.; Falasca, M. Signalling Properties of Inositol Polyphosphates. Molecules 2020, 25, 5281. [CrossRef] [PubMed] 
2. Lee, S.; Kim, M.-G.; Ahn, H.; Kim, S. Inositol Pyrophosphates: Signaling Molecules with Pleiotropic Actions in Mammals. Molecules 2020, 25, 2208. [CrossRef] [PubMed]

3. Chatree, S.; Thongmaen, N.; Tantivejkul, K.; Sitticharoon, C.; Vucenik, I. Role of Inositols and Inositol Phosphates in Energy Metabolism. Molecules 2020, 25, 5079. [CrossRef] [PubMed]

4. Cridland, C.; Gillaspy, G. Inositol Pyrophosphate Pathways and Mechanisms: What Can We Learn from Plants? Molecules 2020, 25, 2789. [CrossRef] [PubMed]

5. Marolt, G.; Kolar, M. Analytical Methods for Determination of Phytic Acid and Other Inositol Phosphates: A Review. Molecules 2021, 26, 174. [CrossRef] [PubMed]

6. Grases, F.; Costa-Bauza, A. Key Aspects of Myo-Inositol Hexaphosphate (Phytate) and Pathological Calcifi-cations. Molecules 2019, 24, 3334. [CrossRef] [PubMed]

7. Aguree, S.; Guo, L.; Reddy, M.B. Phytic Acid Protects from Oxidative Stress Induced by Iron-Overload and High-Fat Diets in B2-Microglobulin Knockout Mice. Molecules 2020, 25, 5331. [CrossRef] [PubMed]

8. Vucenik, I.; Druzijanic, A.; Druzijanic, N. Inositol Hexaphosphate (IP6) and Colon Cancer: From Concepts and First Experiments to Clinical Application. Molecules 2020, 25, 5931. [CrossRef] [PubMed]

9. Bačić, I.; Družijanić, N.; Karlo, R.; Škifić, I.; Jagić, S. Efficacy of IP6 + inositol in the treatment of breast cancer patients receiving chemotherapy: Prospective, randomized, pilot clinical study. J. Exp. Clin. Cancer Res. 2010, 29, 12. [CrossRef] [PubMed]

10. Weinberg, S.E.; Sun, L.Y.; Liao, J.; Yang, G.Y. Overview of Inositol and Inositol Phosphates on Chemo-prevention of Colitis-Induced Carcinogenesis. Molecules 2021, 26, 31. [CrossRef] [PubMed]

11. Kapral, M.; Wawszczyk, J.; Węglarz, L. Regulation of MicroRNA-155 and Its Related Genes Expression by Inositol Hexaphosphate in Colon Cancer Cells. Molecules 2019, 24, 4153. [CrossRef] [PubMed]

12. Omoruyi, F.O.; Stennett, D.; Foster, S.; Dilworth, L. New Frontiers for the Use of IP6 and Inositol Combi-nation in Treating Diabetes Mellitus: A Review. Molecules 2020, 27, 1720. [CrossRef] [PubMed]

13. Mukherjee, S.; Haubner, J.; Chakraborty, A. Targeting the Inositol Pyrophosphate Biosynthetic Enzymes in Metabolic Diseases. Molecules 2020, 25, 1403. [CrossRef]

14. Minini, M.; Senni, A.; Unfer, V.; Bizzarri, M. The Key Role of IP6K: A Novel Target for Anticancer Treatments? Molecules 2020, 25, 4401. [CrossRef] [PubMed]

15. Kamenov, Z.; Gateva, A. Inositols in PCOS. Molecules 2020, 25, 5566. [CrossRef] 